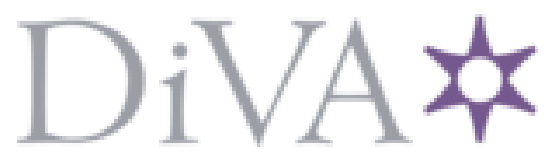

http://www.diva-portal.org

\title{
Postprint
}

This is the accepted version of a paper published in Biofactors. This paper has been peer-reviewed but does not include the final publisher proof-corrections or journal pagination.

Citation for the original published paper (version of record):

Chi, C., Bach, A., Stromgaard, K., Gianni, S., Jemth, P. (2012)

Ligand binding by PDZ domains.

Biofactors, 38(5): 338-348

http://dx.doi.org/10.1002/biof.1031

Access to the published version may require subscription.

N.B. When citing this work, cite the original published paper.

Permanent link to this version:

http://urn.kb.se/resolve?urn=urn:nbn:se:uu:diva- 187852 


\section{Ligand binding by PDZ domains}

Celestine $\mathrm{Chi}^{1}$, Anders Bach ${ }^{2}$, Kristian Strømgaard ${ }^{2}$, Stefano Gianni ${ }^{3}$ and Per Jemth ${ }^{1}$

${ }^{1}$ Department of Medical Biochemistry and Microbiology, Uppsala University, BMC Box 582, SE-75123 Uppsala, Sweden.

${ }^{2}$ Department of Drug Design and Pharmacology, University of Copenhagen, Universitetsparken 2, DK-2100 Copenhagen, Denmark

${ }^{3}$ Istituto Pasteur -Fondazione Cenci Bolognetti and Istituto di Biologia e Patologia Molecolari del CNR, Dipartimento di Scienze Biochimiche "A. Rossi Fanelli", Sapienza Università di Roma, Piazzale A. Moro 5, 00185 Rome, Italy

Corresponding author: Per.Jemth@imbim.uu.se 
The PDZ (Postsynaptic density protein-95/Discs large/Zonula Occludens-1 (1)) protein domain family is one of the most common protein-protein interaction modules in mammalian cells, with paralogs present in several hundred human proteins (2). PDZ domains are found in most cell types, but neuronal proteins for example are particularly rich in these domains (3). The general function of PDZ domains is to bring proteins together within the appropriate cellular compartment, thereby facilitating scaffolding, signalling and trafficking events. The many functions of PDZ domains under normal physiological as well as pathological conditions have been reviewed recently $(3,4)$. In this review we focus on the molecular details of how PDZ domains bind their protein ligands and their potential as drug targets in this context.

\section{Structural details of binding}

PDZ domains consist of roughly 90 amino acid residues, which fold into a globular shape with a $\beta \beta \beta \alpha \beta \beta \alpha \beta$ topology (Fig. 1). The first and last $\beta$-strand form part of a larger $\beta$-sheet and the $\mathrm{C}$ - and N-termini usually connect to other structural units in multi-domain modular enzymes and other proteins $(2,3)$. The binding of PDZ domains to proteins mediates various events, including the formation of protein networks and the immobilization of enzymes at correct intracellular locations. PDZ domains generally bind the C-terminus of target proteins in a shallow pocket between the $\beta 2$ strand and the $\alpha 2$ helix (Fig. 1) $(5,6)$. In doing so the C-terminal residues of the ligand form an extended anti-parallel $\beta$-sheet with $\beta 2$ and $\beta 3$ of the PDZ domain. The C-terminal carboxylate group binds to the backbone of a conserved loop in the PDZ domain, called the carboxylate-binding loop. It is sometimes denoted the GLGF loop due to a well-conserved motif in the sequence responsible for this binding. If the 
carboxylate is replaced with an amide the affinity will drop by two orders of magnitude, showing the importance of a carboxylate in the C-terminus of the ligand (7). The backbone hydrogen bonds of the extended $\beta$-sheet and those of the carboxylate are conserved features of the canonical PDZ-ligand binding (i.e., binding of a C-terminal peptide ligand) and are not believed to add much specificity to the interaction. However, different amino acids could in principle favour certain conformations over others and in this way modulate the affinity. The interactions of the side-chains of the protein ligand with the PDZ domain add further binding energy, in particular those at positions 0 and -2 (counting from the C-terminal, see Fig. 1). It is common to have a hydrophobic side-chain such as Val at position 0 (8) that fits into a hydrophobic pocket in the PDZ domain. However, the contribution to binding from the C-terminal side-chains varies considerably among different PDZ-ligand interactions and will contribute specificity to the binding (8-11).

In addition to the canonical interaction, PDZ domains also bind internal motifs such as a $\beta$-finger in neuronal nitric oxide synthase $(7,12-14)$. In this case a sharp turn between the strands allows binding without a carboxylate, and the first strand of the $\beta$-finger will bind in a similar manner as that of the canonical PDZ-ligand interaction. An internal motif of Dishevelled PDZ was identified by peptide phage display, where an aspartate side chain could replace the carboxylate group, demonstrating that many sequences are potential PDZ ligands. (15).

\section{Specificity and promiscuity}

It has been noted that PDZ domains are typically promiscuous with respect to their binding to the amino acid sequence of a given C-terminal ligand, as demonstrated with designed peptide libraries (10). An early classification based on specificity 
divided PDZ domains into three main classes (I, II and III). However, analysis of all PDZ domains in mouse suggested that such classification is somewhat superficial and that PDZ domains display a broad and overlapping range of specificities (8). Nevertheless, PDZ domains typically require a hydrophobic residue at the C-terminal position of the ligand, which fits into a hydrophobic pocket. Further, a polar residue that hydrogen bonds to a conserved residue(s) in the PDZ domain(s) is often found at position -2 of the ligand. Within these constraints, virtually any amino acid side-chain at positions -1 and -3 would give comparable affinity, on the order of low $\mu \mathrm{M}$ to 0.1 $\mathrm{mM}$.

Given that mammalian genomes encode hundreds of proteins that often contain several PDZ domains, how can specificity be achieved within the cellular context? There is currently no clear answer to this question, but there are a number of suggestions. One explanation is that the combination of residues in the binding site affords enough specific interactions to achieve the necessary selectivity (16), for example through peptide positions -1 and -3 (17). In PSD-95 PDZ3 the Tyr-5 clearly influences the affinity (11) and it is possible and even likely that other residues in the protein ligand could interact with surfaces on the PDZ domain outside of its ligandbinding pocket $(18,19)$. Other factors that might fine-tune the specificity include intradomain allostery and arrangement of PDZ domains into supramodular structures, both of which are discussed in more detail below. In addition, some ligands become available for binding upon activation by, for example, phosphorylation. This is exemplified by phosphorylation of stargazin, an auxiliary subunit of AMPA-type glutamate receptors, which releases the C-terminus from the membrane and allows its binding to PSD-95 (20). However, phosphorylation is a highly versatile regulator of 
PDZ-peptide ligand interaction. Notably, phosphorylation of a Thr within the stargazin PDZ binding motif has the opposite effect, disrupting its ability to bind PSD-95 (21). The regulation of PDZ-ligand interactions by phosphorylation has been discussed in more detail by Lee and Zheng 2010 (22).

However, if all potential cellular ligands were competing for binding to all potential PDZ domains it is unlikely that these mechanisms are sufficient to explain cellular selectivity, thus, compartmentalization is probably a major factor $(10,23)$. For example, within a certain cellular compartment such as the synapse only those PDZ domains and ligands relevant for the scaffolding and signalling would be expressed. Competition for ligands would be reduced and the observed optimized selectivity (8) is sufficient to maintain cellular functions.

\section{Binding of lipids by PDZ domains.}

While the most common interactions mediated by PDZ domains are those with short C-terminal stretches of the target protein, binding to alternative ligands appears to be possible. For example, it is known that some PDZ domains are capable of binding phosphatidylinositol lipids (24). In analogy to the protein-protein interactions mediated by PDZ domains, PDZ-lipid interactions might provide a mechanism for sensing phosphoinositide signalling and regulate the localization of PDZ proteins within membranes (25). The mechanisms of binding and selectivity of PDZ domain and phosphoinositol ligands are generally poorly understood.

In the case of the second PDZ domain from PTP-BL, a splice variant containing a five amino acid insertion at the end of $\beta 2$ undergoes a minor change in conformation that 
decreases the affinity of the PDZ domain for its peptide ligand (26). Interestingly, such a modification positively affects the binding to phosphatidylinositol ligands (27). However, no direct competition experiments have been conducted on PTP-BL PDZ2 and the direct relationships between its lipid and peptide binding awaits further investigation.

One of the most vivid depictions for the mechanism of phosphatidylinositol ligand recognition by PDZ domains has been recently provided for PDZ2 of polychaetoid (28). Zimmermann and co-workers used a combination of modelling, mutagenesis, surface plasmon resonance and localization studies to show that this PDZ domain interacts with phosphatidylinositol phosphates with an apparent affinity in the micromolar range, comparable to PDZ-peptide interactions. Interestingly, the affinity of the interaction increases about 6-fold when the lipid binding experiments are performed in the presence of a peptide ligand of the same PDZ domain. These data indicate that the lipid and peptide binding pockets in PDZ domains are likely to be distinct and may act co-operatively to fine-tune the recognition of the different partners (28). Another lipid-binding PDZ protein is syntenin-1. This protein has two tandem PDZ domains that regulate its plasma membrane localization. Interestingly, the membrane interaction is modulated by phosphorylation of an N-terminal extension as well as by electrostatic interactions through a C-terminal extension of the PDZ tandem (29).

However, by and large, the relationship between the peptide and lipid binding of PDZ domains is still an open question. The structural and biochemical aspects of PDZ-lipid 
interactions and the consequences for peptide interactions have been recently reviewed in more detail $(30,31)$.

\section{Mechanisms of binding}

When a single PDZ domain binds to a peptide corresponding to a cellular ligand, the observed kinetics follow a simple two-state reaction, at least when the ligand (or PDZ domain) is present at concentrations below $100 \mu \mathrm{M}$. It is therefore likely that under cellular conditions the PDZ domain is present either in its ground state or in its ligand bound state, without the presence of any low energy intermediates (Fig. 2). The magnitude of the rate constants for binding is in the order of 1-100 $\mathrm{s}^{-1}$ (dissociation rate constant, $k_{\text {off }}$ ) and around $10^{7} \mathrm{M}^{-1} \mathrm{~s}^{-1}$ (association rate constant, $k_{\mathrm{on}}$ ) at $25^{\circ} \mathrm{C}$. We can extrapolate association and dissociation rate constants at the physiological temperature $\left(37^{\circ} \mathrm{C}\right)$ from experiments at lower temperatures $(32,33)$ to be in the order of $10^{8} \mathrm{M}^{-1} \mathrm{~s}^{-1}$ and $200-1000 \mathrm{~s}^{-1}$, for $k_{\mathrm{on}}$ and $k_{\mathrm{off}}$, respectively. Such rate constants are probably optimal for signalling modules like PDZ domains, where a fast response to an external stimulus may be desirable. The rate constants for the interaction between nNOS PDZ (via its $\beta$-finger) and PSD-95 PDZ2 were measured as $1 \times 10^{7} \mathrm{M}^{-1} \mathrm{~s}^{-1}$ and $8 \mathrm{~s}^{-1}$ at $37{ }^{\circ} \mathrm{C}$ (C.N.C. and P.J., unpublished data), where the lower $k_{\text {on }}$ probably reflects conformational changes during this non-canonical type of binding (see below). It is also clear that PDZ domains generally modulate their affinity by changes in $k_{\text {off }}$ (34), that is, through short-range interactions like hydrogen bonds or hydrophobic interactions rather than long-range charge-charge interactions or conformational equilibria. Furthermore, these short-range interactions form after the major energetic barrier for the binding reaction is overcome, as shown by mutagenesis of peptide ligand side-chains $(14,34)$. However, further studies are needed to 
understand the structural details of the initial events of the binding reaction. Several computational studies have also looked at PDZ-ligand interactions, for example ref. (35), where they observe initial binding for the C-terminal peptide residue. Given the wealth of detailed experimental data, the PDZ domain will most likely serve as a model system for the development of computational predictions of protein-ligand interactions, which will also benefit drug design related to PDZ proteins (discussed below).

In experiments where the peptide ligand concentration was increased to several hundred $\mu \mathrm{M}$, the observed binding kinetics suggested a change in the rate-limiting step, from the bimolecular encounter event to a conformational change, in accordance with the induced fit mechanism $(32,33)$. These experiments were however questioned by NMR experiments, in which the intermediate could not be detected by ${ }^{15} \mathrm{~N}$ relaxation dispersion (36). NMR is a high-resolution technique, but with low sensitivity and at equilibrium the concentration of the proposed intermediate will be low for all concentrations of peptide ligand. It may therefore be below the detection limit of the NMR experiment under the given conditions. In contrast, fluorescence and Förster resonance energy transfer (FRET) are sensitive to very small changes in structure, although give little information about the actual structure itself. Therefore, the conflicting results may be explained by differences in the experimental techniques used. Nonetheless, any structural rearrangements resulting from peptide binding to PDZ domains would be minor, as observed for SAP97 PDZ2 where numerous structures exist with and without ligand(36-40). 
One example of small but significant structural re-arrangements upon ligand binding is that of PDZ2 of syntenin (41). Interestingly, the changes observed by X-ray crystallography were ligand dependent, indicating a possibility for plasticity within the PDZ ligand-binding pocket. Another example is the conformational change in Par-6 PDZ induced by binding of Cdc42 (42), which results in a 10-fold increase in affinity towards a peptide ligand. In both of these examples, the $\alpha 2$ helix experiences a small structural transition, which was also found in NMR experiments with PTP-BL PDZ2 (33). Thus, the position of this helix may be a common way for PDZ domains to modulate the affinity, allosterically as for Par- 6 or through direct interactions upon binding of peptide ligand.

An alternative mechanism by which PDZ domains act as allosteric switches is represented by quality control proteases. Controlled proteolysis is a complex reaction underlying many molecular processes. High Temperature Requirement A (HTRA) proteases are a class of proteases mediating ATP-independent quality control (43). HTRA proteins are characterized by a conserved architecture consisting of a funnelshaped trimer of protease domains, forming a core with protruding PDZ domains (44). Here the PDZ domain plays a critical role both in substrate recognition and in allosteric activation. The first detailed mechanism of HTRA activation was elucidated for bacterial DegS (45). In this case the PDZ domain inhibits DegS activity by directly capturing a loop of the protein. Stress signals ( $\mathrm{C}$ terminal peptides of dislocalized proteins) bind to the PDZ domain and induce a conformational change through displacement of the captured loop, ultimately leading to protease activation.

\section{Sparse energetic networks}


Is it only the binding pocket that determines binding affinity and specificity? It has been suggested that residues distal from the first interaction sphere in PDZ domains could modulate the binding via intradomain allostery (46-50). The word allostery is classically used for multi-subunit proteins where binding of one molecule, for example $\mathrm{CO}_{2}$ in haemoglobin, promotes a structural change that modulates the affinity of another molecule at another site $\left(\mathrm{O}_{2}\right)$. The intradomain energetic cross-talk observed for PDZ domains is perhaps more appropriately denoted as "plastic binding" rather than allostery and could, for example, work through the interactions of sidechains in sparse networks. These interactions may not require conformational transitions, but could rely entirely on changes in side-chain dynamics $(51,52)$. The functional role of such energetic connectivity between amino acid residues has been under debate since Lockless and Ranganathan predicted a sparse energetic network in PDZ domains, based on multiple sequence alignment and statistical coupling analysis (50,53). The PDZ domain family served as a good model system since a large number of sequences from the many hundreds of mammalian homologs were available in the sequence database.. Overlapping or even distinct networks have thereafter been predicted by various computational methods, for example rotamerically induced perturbation (54), perturbation response scanning (55), lattice models (56), molecular dynamics simulations (49) or NMR-constrained molecular dynamics (57) (Fig. 3).

There is experimental evidence for sparse networks in PDZ domains. Lee and coworkers used NMR relaxation methods to demonstrate that certain residues in PTPBL PDZ2 display changes in dynamics upon ligand binding (Fig. 3) or mutagenesis $(46,47)$. In a later work they conclude that dynamics of the PDZ fold might be a conserved feature, which affects function (58). Indeed, modulation of intrinsic 
dynamics upon ligand binding is one plausible mechanism to explain sparse energetic networks. Small but significant changes in chemical shifts upon peptide binding for residues distal from the binding pocket were found for other PDZ domains as well, such as SAP97 PDZ2 (19) and AF-6 PDZ (59).

In another approach, double mutant cycles (60) were constructed to probe for energetic connectivity between two side-chain residues either within the PDZ domain (61) or between residues of the PDZ and those in a cognate peptide ligand (48). Initially no particular network was observed using double mutant cycles with the conserved His372 residue within the PSD-95 PDZ3 domain, but rather a dependence on distance, which questioned the experimental part of the initial paper on sparse networks (50). However, by investigating energetic coupling to residues in the peptide ligand distinct patterns of energetic connectivity in PSD-95 PDZ3 as well as in PTPBL PDZ2 were found (48). These patterns were neither distance dependent nor conserved for the two PDZ domains. They were also different from the co-evolved set of residues, although some residues are common. Moreover, distinct energetic networks can be associated with different peptide residues as observed in the double mutant cycle; for example, for PSD-95 PDZ3, the side-chain at position 0 in the peptide is associated with a network that is distinct from the network associated with position -2. Further, the networks identified in PTP-BL PDZ2 and PSD-95 PDZ3 are distinct from each other. While the precision is high in these experiments there is always a risk that the mutation itself affects any pre-existing energetic network. However, the distinct spatial patterns of the networks suggest that they are not a product of the experimental approach. Importantly, three out of the four energetic networks identified by Gianni et al. (48) had mainly positive coupling energies, 
$\Delta \Delta \Delta G_{\mathrm{C}}$. This means that the first mutation (in the PDZ) decreases the effect of the second mutation (in the peptide) and suggests that the overall arrangement of amino acid side-chains is optimized for binding of a particular ligand side-chain.

We conclude that sparse energetic networks have been predicted and experimentally verified in PDZ domains. Experimental and predicted networks share some common structural regions, but do not always agree (Fig. 3). Such discrepancies may be due to the experimental or computational approach used to find the networks. Nevertheless, these networks may fine-tune the specificity of PDZ domains for their target protein ligands (48), possibly through changes in side-chain dynamics (58). Ultimately, more data, preferably derived from a cellular context, will be necessary to verify the functional significance of these sparse networks.

\section{Functional and structural effects of PDZ domain extensions}

A PDZ domain extension can be described as a structural element immediately before or after the canonical PDZ fold. In terms of structural characteristics, these structural elements could range from $\alpha$-helices or $\beta$-strands to disordered regions. PDZ extensions are common and it is estimated that over $40 \%$ of PDZ domains contain extensions in the $\mathrm{N}$ and/or $\mathrm{C}$ terminus $(62,63)$. As discussed above, the question of how binding specificity is achieved in the PDZ family has challenged the field and the recent discovery that PDZ extensions are very common may help explain how PDZ domains recognize different C-terminal ligands. Apart from stabilizing the overall fold, PDZ extensions modulate function by increasing the interface for ligand binding and/or through dynamic responses. The focus of this section is to describe how some 
PDZ extensions influence binding affinity for PDZ domains, with emphasis on recent experimental data.

One of the most studied PDZ domains, PSD95 PDZ3, has the typical PDZ fold but contains an additional $\alpha$-helix, $\alpha 3$ at its C-terminus (5), which carries a putative phosphorylation site (64). Phosphorylation of the helix leads to its displacement from the canonical part of the PDZ domain. The absence of this helix does not appear to change the overall structure of PSD-95 PDZ3, but its thermodynamic stability is much reduced. In addition, the affinity towards C-terminal peptides is reduced (ca. 20-fold) when the $\alpha 3$ is deleted (65). Isothermal titration calorimetric (ITC) experiments showed that entropy is the main contributing factor to the binding free energy between PSD-95 PDZ3 with a deleted $\alpha 3$ helix and the peptide ligand (65). Further, analysis by NMR showed that this entropy change is due to a dynamic response of the methyl side-chains of the PDZ domain on interaction with the ligand. Our on-going work on the same system shows that the peptide undergoes structural transitions from the unbound to the bound conformations with most of the peptide residues making contact with the protein, including the $\alpha 3$ helix (Chi et al., unpublished). Thus, a combination of a dynamic response and direct interactions to the ligand seem to drive the binding of PSD-95 PDZ3 binding to peptide ligands.

Another well-characterized C-terminal extension is found in PDZ2 of NHERF1, which harbours two helices at its C-terminus, $\alpha 3$ and $\alpha 4$. Bhattacharya et al. (62) used NMR and found resonance shifts in the HQSC spectrum for the NHERF1 PDZ2 wild type in comparison to a variant where the two helices were deleted. The $\alpha 3$ and $\alpha 4$ helices are located far away from the binding pocket, but their deletion drastically reduces the affinity to the ligand, the C-terminal domain of CFTR as well as the 
stability of the PDZ2 domain of NHERF1. This was interpreted as an intramolecular interaction between the core PDZ domain and the $\alpha 3 / \alpha 4$ helices.

A third example is the MAGI PDZ1, where Charbonnier and co-workers (66) determined the structure of MAGI PDZ1 in complex with the ligand, the C-terminal domain of the E6 protein from human papilloma virus by NMR. They showed that the C-terminal extension of MAGI PDZ1, which is highly dynamic and unstructured in solution in the free state, becomes more structured upon interaction with the E6 peptide. In particular they found that residues S113, L114 and V115, in the Cterminal extension, were making intermolecular interactions with the E6 peptide. Mutations introduced at these positions drastically lower the affinity between MAGI PDZ1 and the E6 peptide (66). Other extensions play no obvious functional role; for example, removal of the $\alpha 3$ in the C-terminal extension has no effect on the binding affinity of PDZ3 of ZO-1 to a Cx45 peptide (67), while the flanking SH3 domain has a profound effect as described in the next section. For a more detailed discussion on PDZ extensions, see ref. (63).

\section{PDZ as a modular domain - implications for binding}

It is clear that PDZs often exist as concatemers of two or more domains in a single protein and are also closely associated with non-PDZ type domains such as SH3. How important are adjacent domains for the function of PDZ domains? In some cases it is clear that tandem PDZ domains work as one functional unit, for example the GRIP PDZ1-2 and PDZ4-5 tandems, where one needs the other to fold (68), and the harmonin NPDZ1 domain where the N-domain of harmonin promotes the proper folding of PDZ1 (69). Flanking PDZ domains are also important as they have 
different specificities. For example, in PSD-95, PDZ1, 2 and 3 may bind two or three different proteins simultaneously, e.g., the NMDA receptor, nNOS and CRIPT, respectively (3).

Similarly to the extra structural motifs, flanking domains could also affect binding specificity through allosteric effects or by blocking access to the binding pocket. PDZ1 of PTP-BL interacts with its adjacent domain (PDZ2) and influences the binding specificity of the PDZ2 domain (70). The binding interface between PDZ1 and PDZ2 (at $\alpha 1 / \beta 1$ in PDZ2) is located opposite to the peptide-binding groove. The observed allosteric effect may be transmitted via the energetically connected residues that were identified by double-mutant cycles (48), since this network stretches from the ligand side-chains towards the $\alpha 1 / \beta 1$ surface.

Another well-studied example is the PDZ1-2 tandem of PSD-95. A short linker connects the two PDZ domains and the tandem is thus a well-defined structural unit (71). Moreover, it displays some very interesting dynamic features. Whereas the unbound (apo) PDZ1-2 tandem is essentially rigid, the interdomain motion increases upon binding of peptide as judged by the correlation times for molecular tumbling (72). Intriguingly, this is true even for a bivalent ligand (73), which intuitively should restrict inter-domain dynamics. Such increased dynamics in the ligand-bound state might increase the affinity of the complex by decreasing the entropic penalty on binding. However, in terms of binding to peptide ligands this tandem PDZ appears to function as the sum of the respective PDZ-ligand interaction, or only slightly better (74). It is thus unclear how the observed increase in dynamics would influence function. In another study the effect of all three PDZ domains of SAP97 on the 
binding kinetics was assessed with the C-terminal domain of the human papillomavirus E6 protein as ligand (19). Similarly to the PSD-95 PDZ1-2 tandem, the combined effect of the three domains is relatively well described by the sum of the individual domains, but with an apparent association rate constant somewhat lower than expected for the SAP97 PDZ1-2 tandem and somewhat higher for the SAP97 PDZ2-3 tandem. The data were consistent with a small angle X-ray scattering (SAXS) model of the three connected PDZ domains (75), which showed that a protein ligand may experience restricted access to one or both of PDZ1-2 of SAP97.

What is the influence of non-PDZ protein domains flanking the PDZ domains? Recent data support the concept of a supramodule as the functional unit of some PDZ domains. Pan et al. (67) and Nomme et al. (76) demonstrated that, in the scaffolding protein ZO-1, the flanking SH3 domain (Fig. 1) improves binding of PDZ3 to its ligands, Cx45 or JAM-A, respectively. Deletion of the SH3-GK resulted in decreased binding affinity by one order of magnitude to the $\mathrm{Cx} 45$ peptide, while binding to JAM-A could not be detected in NMR experiments, showing the importance of the adjacent SH3 in the supramodule. Residues in the $\alpha 2$ helix, in the $\beta 2 / \beta 3$ loop of PDZ3, and in the linker region between PDZ3 and SH3 make direct interaction to F519 from $\beta 1$, W557 from $\beta 3$, and N576 preceding $\alpha$ A in SH3.

It is clear that neighbouring domains may influence the PDZ-ligand interaction. Thus, future experiments on such supramodules and on full-length PDZ proteins are necessary to understand in more detail how PDZ domains interact with their protein ligands in the context of the cell. In this respect the nature of the ligand should also be considered, while a short peptide may have full access to the binding groove, the 
natural protein ligand may not. A comprehensive review on PDZ supramodules is available (3).

Interestingly, the potential of PDZ domains interacting with each other has only recently been systematically investigated. Chang et al. performed a study of almost all mouse PDZ domains and systematically probed all possible PDZ-PDZ interactions (77). Previously it has been demonstrated that for example PDZ6 of GRIP1 and PDZ1 and PDZ2 of NHERF1 dimerize in a back-to-back fashion, leaving the peptidebinding groove available for canonical interaction $(78,79)$. Chang et al. (77) demonstrated that the prevalence of such PDZ-PDZ interactions is highly frequent with $30 \%$ of mammalian PDZ domains engaging in such interactions. The functional consequences of these findings will be the subject of future studies.

\section{PDZ domains as drug targets}

Since PDZ domains are instrumental in numerous important biological processes as scaffolding proteins that regulate signal transduction and as mediators of trafficking membrane proteins, they have obvious potential as drug targets. Thus, several PDZ domain proteins have been suggested as putative drug targets, primarily for neurological diseases, for example PSD-95 (80), PICK1 (81) and Shank3 (82), and to cancers, for example AF6 (83), MAGI3 (84), NHERF1 (85), MINT1 (86), SAP97 (19), Dvl1 (87) and GIPC (88).

Inhibition of intracellular protein-protein interactions provides a more subtle approach to perturb signalling pathways than targeting for example integral membrane proteins 
directly, where the entire signalling cascade down-stream of the receptor is affected. Thus, inhibitors of protein-protein interaction are believed to mediate their biological effects with increased meticulousness, thereby potentially providing an efficient and safe profile. However, targeting protein-protein interactions has been perceived difficult, due to the generally large and flat protein-surfaces involved in such interactions (89).

Similar to other protein-protein interactions, those of PDZ domains have appeared difficult to target with small molecules. The primary reason is the nature of the PDZ domain binding pocket, which is relatively elongated and shallow $(90,91)$. PDZ domains therefore represent a veritable challenge for developing drug-like small molecule inhibitors, and seem best suited for peptide-like structures. This is exemplified by screening studies, which have failed to provide small molecule hits: Screening a library of 100,000 compounds against the MINT1 PDZ domain led only to false positives (86), and NMR screening of 11,759 fragment-like compounds against PSD-95, a method also used to evaluate the druggability of the studied targets, did not provide any hits (91). In the cases where small molecule inhibitors have been identified, either by screening $(81-83,92)$ or by rational design $(84,85,93-98)$, the affinities did not surpass the low $\mu \mathrm{M}$ range, even after subsequent structure-activity relationship (SAR) studies, where small modifications are made to the inhibitors and evaluated $(82,83,96,97,99)$ (Fig. 4).

A principally different strategy has been to use the natural C-terminal peptide ligand of the PDZ domain of interest as a template for development of inhibitors. Although peptides have generally not been considered optimal drug candidates, this perception 
is changing and an increasing number of peptide drugs are now emerging. The clinically most advanced PDZ domain inhibitor is a 20-mer peptide, Tat-NR2B9c (or NA-1), which consists of an 11-mer Tat sequence that facilitates blood-brain barrier permeability combined with the nine C-terminal amino acids from the GluN2B subunit of the NMDA receptor ascertaining binding to the PDZ1 and PDZ2 domains, respectively, of PSD-95 $(80,100)$. NA-1 has recently been investigated in a phase II clinical trials for the treatment of cerebral ischemia, however, NA-1 only binds with low affinity towards PSD-95 $\left[K_{\mathrm{i}}=4 \mu \mathrm{M}\right.$ against PSD-95 PDZ2 (101)], which might impede further development or clinical potential. This problem of low affinity of PDZ inhibitors was recently addressed by dimeric inhibitors, which exploit that PDZ1 and PDZ2 of PSD-95 exist as tandem domains (3). Thus, by covalently linking two peptide ligands (low $\mu \mathrm{M}$ affinity) with a monodisperse polyethylene glycol (PEG) linker of optimal length, a 145-fold increase in affinity towards PSD-95 PDZ1-2 $\left(K_{\mathrm{i}}=\right.$ $10 \mathrm{nM}$ ) relative to the respective monomeric peptide ligand was achieved, along with increased in vitro stability in blood plasma (102). In subsequent studies, the PEG linker was modified to enable direct attachment of a Tat sequence to the linker, and the resulting 'Tat- $N$-dimer' demonstrated unprecedented affinity towards the PDZ tandem $\left(K_{\mathrm{i}}=4.6 \mathrm{nM}\right)$ (Fig. 4), as well as enhanced neuroprotective properties compared to Tat-NR2B9c in a mouse model of ischemic brain damage (73). Two other types of dimeric inhibitors targeting PSD-95 have been developed using similar principles to those described above, and in both cases 3-20 fold affinity improvement against PDZ1-2 was observed relative to the respective monomeric ligands $\left[\mathrm{ED}_{50}=\right.$ $5.5 \mu \mathrm{M}(71)$; and $\left.K_{\mathrm{i}}=0.81 \mu \mathrm{M}(103)\right]$ (Fig. 4). 
Peptidomimetic approaches to develop PDZ domains inhibitors using the C-terminal peptide ligand as starting point must address the inherent challenges of peptides as drugs, namely their instability and hydrophilicity. A number of different approaches have been employed including cyclization of the peptide $(104,105)$, introduction of unnatural amino acids $(88,106)$ or side-chain-to-backbone modifications $(107)$, and replacement of specific amide bonds with thioamides (108). These chemical modifications have in several cases led to ligands with increased protease-stability and improved affinity (Fig. 4).

Thus, although PDZ domains are obvious and attractive drugs targets, it has proven demanding to identify drug-like inhibitors. Currently, the conventional peptide ligand Tat-NR2B9c (NA-1) is the most advanced inhibitor, but it faces challenges, in particular with regard to affinity. Alternatively, high-affinity and in vivo active dimeric ligands, such as Tat- $N$-dimer, have been developed, which have the additional advantage of increased selectivity by targeting tandem, rather than individual PDZ domains. In addition, peptidomimetic ligands might also prove attractive for further development of therapeutic compounds that target PDZ domains.

\section{Conclusions}

Future research should focus on resolving the remaining issues regarding the specificity in PDZ-ligand interactions. In particular, what is the role of PDZ tandems and supramodules? Are the sparse energetic networks of physiological importance? These questions must also be addressed within a cellular context to elucidate the relevance of compartmentalization. The answers to these questions may guide future 
approaches to design drugs targeting PDZ domains, for example by designing multivalent inhibitors of both PDZ domains and other neighbouring domains.

\section{Acknowledgements}

This work was supported by the Swedish Research Council (P.J.), the Danish Council for Independent Research (Technology and Production Sciences) (A.B.), the Lundbeck Foundation (K.S.), and by the Italian Ministero dell'Istruzione dell'Universita`e della Ricerca (Progetto di Interesse 'Invecchiamento' (to S.G.)

\section{References}

[1] Kennedy, M. B. (1995) Origin of PDZ (DHR, GLGF) domains. Trends Biochem. Sci. 20, 350.

[2] Nourry, C., Grant, S. G., Borg, J. P. (2003) PDZ domain proteins: plug and play! Sci STKE 2003, 1-12.

[3] Feng, W., Zhang, M. (2009) Organization and dynamics of PDZ-domainrelated supramodules in the postsynaptic density. Nat. Rev. Neurosci. 10, 8799.

[4] Subbaiah, V. K., Kranjec, C., Thomas, M., Banks, L. (2011) PDZ domains: the building blocks regulating tumorigenesis. The Biochemical journal 439, 195-205.

[5] Doyle, D. A., Lee, A., Lewis, J., Kim, E., Sheng, M., MacKinnon, R. (1996) Crystal structures of a complexed and peptide-free membrane protein-binding domain: molecular basis of peptide recognition by PDZ. Cell 85, 1067-1076.

[6] Jemth, P., Gianni, S. (2007) PDZ domains: folding and binding. Biochemistry 46, 8701-8708.

[7] Harris, B. Z., Hillier, B. J., Lim, W. A. (2001) Energetic determinants of internal motif recognition by PDZ domains. Biochemistry 40, 5921-5930.

[8] Stiffler, M. A., Chen, J. R., Grantcharova, V. P., Lei, Y., Fuchs, D., Allen, J. E., Zaslavskaia, L. A., MacBeath, G. (2007) PDZ domain binding selectivity is optimized across the mouse proteome. Science 317, 364-369.

[9] Skelton, N. J., Koehler, M. F. T., Zobel, K., Wong, W. L., Yeh, S., Pisabarro, M. T., Yin, J. P., Lasky, L. A., Sidhu, S. S. (2003) Origins of PDZ domain ligand specificity. Structure determination and mutagenesis of the erbin PDZ domain. J. Biol. Chem. 278, 7645-7654.

[10] Wiedemann, U., Boisguerin, P., Leben, R., Leitner, D., Krause, G., Moelling, K., Volkmer-Engert, R., Oschkinat, H. (2004) Quantification of PDZ domain specificity, prediction of ligand affinity and rational design of super-binding peptides. J. Mol. Biol. 343, 703-718.

[11] Saro, D., Li, T., Rupasinghe, C., Paredes, A., Caspers, N., Spaller, M. R. (2007) A thermodynamic ligand binding study of the third PDZ domain 
(PDZ3) from the mammalian neuronal protein PSD-95. Biochemistry In press.

[12] Hillier, B. J., Christopherson, K. S., Prehoda, K. E., Bredt, D. S., Lim, W. A. (1999) Unexpected modes of PDZ domain scaffolding revealed by structure of nNOS-syntrophin complex. Science 284, 812-815.

[13] Tochio, H., Mok, Y. K., Zhang, Q., Kan, H. M., Bredt, D. S., Zhang, M. (2000) Formation of nNOS/PSD-95 PDZ dimer requires a preformed betafinger structure from the nNOS PDZ domain. J. Mol. Biol. 303, 359-370.

[14] Karlsson, O. A., Chi, C. N., Engström, Å., Jemth, P. (2012) The transition state for coupled folding and binding for a flexible beta finger. J. Mol. Biol. In press

[15] Zhang, Y., Appleton, B. A., Wiesmann, C., Lau, T., Costa, M., Hannoush, R. N., Sidhu, S. S. (2009) Inhibition of Wnt signaling by Dishevelled PDZ peptides. Nat. Chem. Biol. 5, 217-219.

[16] Kaneko, T., Sidhu, S. S., Li, S. S. C. (2011) Evolving specificity from variability for protein interaction domains. Trends Biochem. Sci. 36, 183-190.

[17] Sakarya, O., Conaco, C., Egecioglu, O., Solla, S. A., Oakley, T. H., Kosik, K. S. (2010) Evolutionary expansion and specialization of the PDZ domains. Mol. Biol. Evol. 27, 1058-1069.

[18] Lim, I. A., Hall, D. D., Hell, J. W. (2002) Selectivity and promiscuity of the first and second PDZ domains of PSD-95 and synapse-associated protein 102. J. Biol. Chem. 277, 21697-21711.

[19] Chi, C. N., Bach, A., Engstrom, A., Stromgaard, K., Lundstrom, P., Ferguson, N., Jemth, P. (2011) Biophysical characterization of the complex between human papillomavirus E6 protein and synapse-associated protein 97. J Biol Chem 286, 3597-3606.

[20] Opazo, P., Sainlos, M., Choquet, D. (2011) Regulation of AMPA receptor surface diffusion by PSD-95 slots. Curr. Opin. Neurobiol.

[21] Jackson, A. C., Nicoll, R. A. (2011) The expanding social network of ionotropic glutamate receptors: TARPs and other transmembrane auxiliary subunits. Neuron 70, 178-199.

[22] Lee, H. J., Zheng, J. J. (2010) PDZ domains and their binding partners: structure, specificity, and modification. Cell Commun. Signal. 8, 8.

[23] Te Velthuis, A. J., Sakalis, P. A., Fowler, D. A., Bagowski, C. P. (2011) Genome-Wide Analysis of PDZ Domain Binding Reveals Inherent Functional Overlap within the PDZ Interaction Network. PLoS ONE 6, e16047.

[24] Zimmermann, P., Meerschaert, K., Reekmans, G., Leenaerts, I., Small, J. V., Vandekerckhove, J., David, G., Gettemans, J. (2002) PIP(2)-PDZ domain binding controls the association of syntenin with the plasma membrane. Mol. Cell. 9, 1215-1225.

[25] Pan, L., Wu, H., Shen, C., Shi, Y., Jin, W., Xia, J., Zhang, M. (2007) Clustering and synaptic targeting of PICK1 requires direct interaction between the PDZ domain and lipid membranes. EMBO J. 26, 4576-4587.

[26] Walma, T., Aelen, J., Nabuurs, S. B., Oostendorp, M., van den Berk, L., Hendriks, W., Vuister, G. W. (2004) A closed binding pocket and global destabilization modify the binding properties of an alternatively spliced form of the second PDZ domain of PTP-BL. Structure 12, 11-20.

[27] Kachel, N., Erdmann, K. S., Kremer, W., Wolff, P., Gronwald, W., Heumann, R., Kalbitzer, H. R. (2003) Structure determination and ligand interactions of 
the PDZ2b domain of PTP-Bas (hPTP1E): splicing-induced modulation of ligand specificity. J. Mol. Biol. 334, 143-155.

[28] Ivarsson, Y., Wawrzyniak, A. M., Wuytens, G., Kosloff, M., Vermeiren, E., Raport, M., Zimmermann, P. (2011) Cooperative phosphoinositide and peptide binding by PSD-95/discs large/ZO-1 (PDZ) domain of polychaetoid, Drosophila zonulin. J. Biol. Chem. 286, 44669-44678.

[29] Wawrzyniak, A. M., Vermeiren, E., Zimmermann, P., Ivarsson, Y. (2012) Extensions of PSD-95/discs large/ZO-1 (PDZ) domains influence lipid binding and membrane targeting of syntenin-1. FEBS Lett. In press

[30] Gallardo, R., Ivarsson, Y., Schymkowitz, J., Rousseau, F., Zimmermann, P. (2010) Structural diversity of PDZ-lipid interactions. Chembiochem 11, 456467.

[31] Ivarsson, Y. (2012) Plasticity of PDZ domains in ligand recognition and signaling. FEBS Lett. In press

[32] Chi, C. N., Bach, A., Engström, Å., Wang, H., Strømgaard, K., Gianni, S., Jemth, P. (2009) A sequential binding mechanism in a PDZ domain. Biochemistry 48, 7089-7097.

[33] Gianni, S., Walma, T., Arcovito, A., Calosci, N., Bellelli, A., Engstrom, A., Travaglini-Allocatelli, C., Brunori, M., Jemth, P., Vuister, G. W. (2006) Demonstration of long-range interactions in a PDZ domain by NMR, kinetics, and protein engineering. Structure 14, 1801-1809.

[34] Haq, S. R., Chi, C. N., Bach, A., Dogan, J., Engström, Å., Hultqvist, G., Karlsson, A., Lundström, P., Montemiglio, L. C., Strømgaard, K., Gianni, S., Jemth, P. (2012) Side-chain interactions form late and cooperatively in the binding reaction between disordered peptides and PDZ domains. J. Am. Chem. Soc. In press

[35] Staneva, I., Wallin, S. (2011) Binding free energy landscape of domainpeptide interactions. PLoS Comput. Biol. 7, e1002131.

[36] Zhang, J., Sapienza, P. J., Ke, H., Chang, A., Hengel, S. R., Wang, H., Phillips, G. N., Lee, A. L. (2010) Crystallographic and nuclear magnetic resonance evaluation of the impact of peptide binding to the second PDZ domain of protein tyrosine phosphatase 1E. Biochemistry 49, 9280-9291.

[37] Liu, Y., Henry, G. D., Hegde, R. S., Baleja, J. D. (2007) Solution structure of the hDlg/SAP97 PDZ2 domain and its mechanism of interaction with HPV-18 papillomavirus E6 protein. Biochemistry 46, 10864-10874.

[38] von Ossowski, I., Oksanen, E., von Ossowski, L., Cai, C., Sundberg, M., Goldman, A., Keinänen, K. (2006) Crystal structure of the second PDZ domain of SAP97 in complex with a GluR-A C-terminal peptide. FEBS J. 273, 5219-5229.

[39] Zhang, Y., Dasgupta, J., Ma, R. Z., Banks, L., Thomas, M., Chen, X. S. (2007) Structures of a human papillomavirus (HPV) E6 polypeptide bound to MAGUK proteins: mechanisms of targeting tumor suppressors by a high-risk HPV oncoprotein. J. Virol. 81, 3618-3626.

[40] Haq, S. R., Jürgens, M. C., Chi, C. N., Koh, C. S., Elfström, L., Selmer, M., Gianni, S., Jemth, P. (2010) The plastic energy landscape of protein folding: a triangular folding mechanism with an equilibrium intermediate for a small protein domain. J. Biol. Chem. 285, 18051-18059.

[41] Grembecka, J., Cierpicki, T., Devedjiev, Y., Derewenda, U., Kang, B. S., Bushweller, J. H., Derewenda, Z. S. (2006) The binding of the PDZ tandem of syntenin to target proteins. Biochemistry 45, 3674-3683. 
[42] Peterson, F. C., Penkert, R. R., Volkman, B. F., Prehoda, K. E. (2004) Cdc42 regulates the Par-6 PDZ domain through an allosteric CRIB-PDZ transition. Mol Cell 13, 665-676.

[43] Clausen, T., Kaiser, M., Huber, R., Ehrmann, M. (2011) HTRA proteases: regulated proteolysis in protein quality control. Nat. Rev. Mol. Cell Biol. 12, 152-162.

[44] Wilken, C., Kitzing, K., Kurzbauer, R., Ehrmann, M., Clausen, T. (2004) Crystal structure of the DegS stress sensor: How a PDZ domain recognizes misfolded protein and activates a protease. Cell 117, 483-494.

[45] Hasselblatt, H., Kurzbauer, R., Wilken, C., Krojer, T., Sawa, J., Kurt, J., Kirk, R., Hasenbein, S., Ehrmann, M., Clausen, T. (2007) Regulation of the sigmaE stress response by DegS: how the PDZ domain keeps the protease inactive in the resting state and allows integration of different OMP-derived stress signals upon folding stress. Genes Dev 21, 2659-2670.

[46] Fuentes, E. J., Der, C. J., Lee, A. L. (2004) Ligand-dependent dynamics and intramolecular signaling in a PDZ domain. J. Mol. Biol. 335, 1105-1115.

[47] Fuentes, E. J., Gilmore, S. A., Mauldin, R. V., Lee, A. L. (2006) Evaluation of energetic and dynamic coupling networks in a PDZ domain protein. J. Mol. Biol. 364, 337-351.

[48] Gianni, S., Haq, S. R., Montemiglio, L. C., Jurgens, M. C., Engstrom, A., Chi, C. N., Brunori, M., Jemth, P. (2011) Sequence-specific Long Range Networks in PSD-95/Discs Large/ZO-1 (PDZ) Domains Tune Their Binding Selectivity. $J$ Biol Chem 286, 27167-27175.

[49] Kong, Y., Karplus, M. (2009) Signaling pathways of PDZ2 domain: a molecular dynamics interaction correlation analysis. Proteins 74, 145-154.

[50] Lockless, S. W., Ranganathan, R. (1999) Evolutionary conserved pathways of energetic connectivity in protein families. Science 286, 295-299.

[51] Clarkson, M. W., Gilmore, S. A., Edgell, M. H., Lee, A. L. (2006) Dynamic coupling and allosteric behavior in a nonallosteric protein. Biochemistry 45, 7693-7699.

[52] Clarkson, M. W., Lee, A. L. (2004) Long-range dynamic effects of point mutations propagate through side chains in the serine protease inhibitor eglin c. Biochemistry 43, 12448-12458.

[53] Fodor, A. A., Aldrich, R. W. (2004) On evolutionary conservation of thermodynamic coupling in proteins. J. Biol. Chem. 279, 19046-19050.

[54] Ho, B. K., Agard, D. A. (2010) Conserved tertiary couplings stabilize elements in the PDZ fold, leading to characteristic patterns of domain conformational flexibility. Protein Sci. 19, 398-411.

[55] Gerek, Z. N., Ozkan, S. B. (2011) Change in allosteric network affects binding affinities of PDZ domains: analysis through perturbation response scanning. PLoS Comput. Biol. 7, e1002154.

[56] Liu, Z., Chen, J., Thirumalai, D. (2009) On the accuracy of inferring energetic coupling between distant sites in protein families from evolutionary imprints: illustrations using lattice model. Proteins 77, 823-831.

[57] Dhulesia, A., Gsponer, J., Vendruscolo, M. (2008) Mapping of two networks of residues that exhibit structural and dynamical changes upon binding in a PDZ domain protein. J. Am. Chem. Soc. 130, 8931-8939.

[58] Law, A. B., Fuentes, E. J., Lee, A. L. (2009) Conservation of side-chain dynamics within a protein family. J. Am. Chem. Soc. 131, 6322-6323. 
[59] Niu, X., Chen, Q., Zhang, J., Shen, W., Shi, Y., Wu, J. (2007) Interesting structural and dynamical behaviors exhibited by the AF-6 PDZ domain upon Bcr peptide binding. Biochemistry 46, 15042-15053.

[60] Horovitz, A., Fersht, A. R. (1990) Strategy for analysing the co-operativity of intramolecular interactions in peptides and proteins. J. Mol. Biol. 214, 613617.

[61] Chi, C. N., Elfström, L., Shi, Y., Snäll, T., Engström, Å., Jemth, P. (2008) Reassessing a sparse energetic network within a single protein domain. Proc. Natl. Acad. Sci. USA 105, 4679-4684.

[62] Bhattacharya, S., Dai, Z., Li, J., Baxter, S., Callaway, D. J., Cowburn, D., Bu, Z. (2010) A conformational switch in the scaffolding protein NHERF1 controls autoinhibition and complex formation. J. Biol. Chem. 285, 99819994.

[63] Wang, C. K., Pan, L., Chen, J., Zhang, M. (2010) Extensions of PDZ domains as important structural and functional elements. Protein Cell 1, 737-751.

[64] Zhang, J., Petit, C. M., King, D. S., Lee, A. L. (2011) Phosphorylation of a PDZ domain extension modulates binding affinity and interdomain interactions in postsynaptic density-95 (PSD-95) protein, a membraneassociated guanylate kinase (MAGUK). J. Biol. Chem. 286, 41776-41785.

[65] Petit, C. M., Zhang, J., Sapienza, P. J., Fuentes, E. J., Lee, A. L. (2009) Hidden dynamic allostery in a PDZ domain. Proc. Natl. Acad. Sci. U.S.A. 106, 18249-18254.

[66] Charbonnier, S., Nomine, Y., Ramirez, J., Luck, K., Chapelle, A., Stote, R. H., Trave, G., Kieffer, B., Atkinson, R. A. (2011) The structural and dynamic response of MAGI-1 PDZ1 with noncanonical domain boundaries to the binding of human papillomavirus E6. J. Mol. Biol. 406, 745-763.

[67] Pan, L., Chen, J., Yu, J., Yu, H., Zhang, M. (2011) The structure of the PDZ3SH3-GuK tandem of ZO-1 protein suggests a supramodular organization of the membrane-associated guanylate kinase (MAGUK) family scaffold protein core. J. Biol. Chem. 286, 40069-40074.

[68] Feng, W., Shi, Y., Li, M., Zhang, M. (2003) Tandem PDZ repeats in glutamate receptor-interacting proteins have a novel mode of PDZ domainmediated target binding. Nat. Struct. Biol. 10, 972-978.

[69] El-Amraoui, A., Petit, C. (2005) Usher I syndrome: unravelling the mechanisms that underlie the cohesion of the growing hair bundle in inner ear sensory cells. J. Cell Sci. 118, 4593-4603.

[70] van den Berk, L. C., Landi, E., Walma, T., Vuister, G. W., Dente, L., Hendriks, W. J. (2007) An allosteric intramolecular PDZ-PDZ interaction modulates PTP-BL PDZ2 binding specificity. Biochemistry 46, 13629-13637.

[71] Long, J. F., Tochio, H., Wang, P., Fan, J. S., Sala, C., Niethammer, M., Sheng, M., Zhang, M. (2003) Supramodular structure and synergistic target binding of the N-terminal tandem PDZ domains of PSD-95. J. Mol. Biol. 327, 203214.

[72] Wang, W., Weng, J., Zhang, X., Liu, M., Zhang, M. (2009) Creating conformational entropy by increasing interdomain mobility in ligand binding regulation: a revisit to N-terminal tandem PDZ domains of PSD-95. J. Am. Chem. Soc. 131, 787-796.

[73] Bach, A., Clausen, B. H., Møller, M., Vestergaard, B., Chi, C. N., Round, A., Sørensen, P. L., Nissen, K. B., Kastrup, J. S., Gajhede, M., Jemth, P., Kristensen, A. S., Lundström, P., Lambertsen, K. L., Strømgaard, K. (2012) A 
high-affinity, dimeric inhibitor of PSD-95 bivalently interacts with PDZ1-2 and protects against ischemic brain damage. Proc. Natl. Acad. Sci. U. S. A. 109, accepted.

[74] Chi, C. N., Bach, A., Gottschalk, M., Kristensen, A. S., Stromgaard, K., Jemth, P. (2010) Deciphering the kinetic binding mechanism of dimeric ligands using a potent plasma-stable dimeric inhibitor of postsynaptic density protein-95 as an example. J. Biol. Chem. 285, 28252-28260.

[75] Goult, B. T., Rapley, J. D., Dart, C., Kitmitto, A., Grossmann, J. G., Leyland, M. L., Lian, L. Y. (2007) Small-angle X-ray scattering and NMR studies of the conformation of the PDZ region of SAP97 and its interactions with Kir2.1. Biochemistry 46, 14117-14128.

[76] Nomme, J., Fanning, A. S., Caffrey, M., Lye, M. F., Anderson, J. M., Lavie, A. (2011) The Src homology 3 domain is required for junctional adhesion molecule binding to the third PDZ domain of the scaffolding protein ZO-1. J. Biol. Chem. 286, 43352-43360.

[77] Chang, B. H., Gujral, T. S., Karp, E. S., BuKhalid, R., Grantcharova, V. P., MacBeath, G. (2011) A systematic family-wide investigation reveals that $\sim 30 \%$ of mammalian PDZ domains engage in PDZ-PDZ interactions. Chem. Biol. 18, 1143-1152.

[78] Fouassier, L., Yun, C. C., Fitz, J. G., Doctor, R. B. (2000) Evidence for ezrinradixin-moesin-binding phosphoprotein 50 (EBP50) self-association through PDZ-PDZ interactions. J. Biol. Chem. 275, 25039-25045.

[79] Im, Y. J., Park, S. H., Rho, S. H., Lee, J. H., Kang, G. B., Sheng, M., Kim, E., Eom, S. H. (2003) Crystal structure of GRIP1 PDZ6-peptide complex reveals the structural basis for class II PDZ target recognition and PDZ domainmediated multimerization. J. Biol. Chem. 278, 8501-8507.

[80] Aarts, M., Liu, Y., Liu, L., Besshoh, S., Arundine, M., Gurd, J. W., Wang, Y. T., Salter, M. W., Tymianski, M. (2002) Treatment of ischemic brain damage by perturbing NMDA receptor- PSD-95 protein interactions. Science 298, 846-850.

[81] Thorsen, T. S., Madsen, K. L., Rebola, N., Rathje, M., Anggono, V., Bach, A., Moreira, I. S., Stuhr-Hansen, N., Dyhring, T., Peters, D., Beuming, T., Huganir, R., Weinstein, H., Mulle, C., Stromgaard, K., Ronn, L. C., Gether, U. (2010) Identification of a small-molecule inhibitor of the PICK1 PDZ domain that inhibits hippocampal LTP and LTD. Proc Natl Acad Sci U S A 107, 413418.

[82] Saupe, J., Roske, Y., Schillinger, C., Kamdem, N., Radetzki, S., Diehl, A., Oschkinat, H., Krause, G., Heinemann, U., Rademann, J. (2011) Discovery, structure-activity relationship studies, and crystal structure of nonpeptide inhibitors bound to the Shank3 PDZ domain. ChemMedChem 6, 1411-1422.

[83] Joshi, M., Vargas, C., Boisguerin, P., Diehl, A., Krause, G., Schmieder, P., Moelling, K., Hagen, V., Schade, M., Oschkinat, H. (2006) Discovery of lowmolecular-weight ligands for the AF6 PDZ domain. Angew. Chem. Int. Ed 45, 3790-3795.

[84] Fujii, N., Haresco, J. J., Novak, K. A., Stokoe, D., Kuntz, I. D., Guy, R. K. (2003) A selective irreversible inhibitor targeting a PDZ protein interaction domain. J. Am. Chem. Soc. 125, 12074-12075.

[85] Mayasundari, A., Ferreira, A. M., He, L., Mahindroo, N., Bashford, D., Fujii, N. (2008) Rational design of the first small-molecule antagonists of NHERF1/EBP50 PDZ domains. Bioorg. Med. Chem. Lett. 18, 942-945. 
[86] Chen, X., Longgood, J. C., Michnoff, C., Wei, S., Frantz, D. E., Bezprozvanny, L. (2007) High-throughput screen for small molecule inhibitors of Mint1-PDZ domains. Assay Drug Dev. Technol. 5, 769-783.

[87] Shan, J., Shi, D. L., Wang, J., Zheng, J. (2005) Identification of a specific inhibitor of the dishevelled PDZ domain. Biochemistry 44, 15495-15503.

[88] Patra, C. J., Rupasinghe, C. N., Dutta, S. K., Bhattacharya, S., Wang, E., Spaller, M. R., Mukhopadhyay, D. (2012) Chemically modified peptides targeting the PDZ domain of GIPC as a therapeutic approach for cancer. ACS Chem. Biol. In press

[89] Wells, J. A., McClendon, C. L. (2007) Reaching for high-hanging fruit in drug discovery at protein-protein interfaces. Nature 450, 1001-1009.

[90] Fry, D. C., Vassilev, L. T. (2005) Targeting protein-protein interactions for cancer therapy. J. Mol. Med. 83, 955-963.

[91] Hajduk, P. J., Huth, J. R., Fesik, S. W. (2005) Druggability indices for protein targets derived from NMR-based screening data. J. Med. Chem. 48, 25182525 .

[92] Thorsen, T. S., Madsen, K. L., Dyhring, T., Bach, A., Peters, D., Stromgaard, K., Ronn, L. C., Gether, U. (2011) A fluorescence polarization based screening assay for identification of small molecule inhibitors of the PICK1 PDZ domain. Comb. Chem. High Throughput Screen. 14, 590-600.

[93] Fujii, N., Haresco, J. J., Novak, K. A., Gage, R. M., Pedemonte, N., Stokoe, D., Kuntz, I. D., Guy, R. K. (2007) Rational design of a nonpeptide general chemical scaffold for reversible inhibition of PDZ domain interactions. Bioorg. Med. Chem. Lett. 17, 549-552.

[94] Fujii, N., You, L., Xu, Z., Uematsu, K., Shan, J., He, B., Mikami, I., Edmondson, L. R., Neale, G., Zheng, J., Guy, R. K., Jablons, D. M. (2007) An antagonist of dishevelled protein-protein interaction suppresses beta-catenindependent tumor cell growth. Cancer Res 67, 573-579.

[95] Grandy, D., Shan, J., Zhang, X., Rao, S., Akunuru, S., Li, H., Zhang, Y., Alpatov, I., Zhang, X. A., Lang, R. A., Shi, D. L., Zheng, J. J. (2009) Discovery and characterization of a small molecule inhibitor of the PDZ domain of dishevelled. J Biol Chem 284, 16256-16263.

[96] Shan, J., Zheng, J. J. (2009) Optimizing Dvl PDZ domain inhibitor by exploring chemical space. J Comput Aided Mol Des 23, 37-47.

[97] Shan, J., Zhang, X., Bao, J., Cassell, R., Zheng, J. J. (2012) Synthesis of potent dishevelled PDZ domain inhibitors guided by virtual screening and NMR studies. Chem. Biol. Drug Des. 79, 376-383.

[98] Lee, H. J., Wang, N. X., Shi, D. L., Zheng, J. J. (2009) Sulindac inhibits canonical Wnt signaling by blocking the PDZ domain of the protein Dishevelled. Angew. Chem. Int. Ed. Engl. 48, 6448-6452.

[99] Bach, A., Stuhr-Hansen, N., Thorsen, T. S., Bork, N., Moreira, I. S., Frydenvang, K., Padrah, S., Christensen, S. B., Madsen, K. L., Weinstein, H., Gether, U., Stromgaard, K. (2010) Structure-activity relationships of a smallmolecule inhibitor of the PDZ domain of PICK1. Org. Biomol. Chem. 8, 42814288 .

[100] Cook, D. J., Teves, L., Tymianski, M. (2012) Treatment of stroke with a PSD95 inhibitor in the gyrencephalic primate brain. Nature 483, 213-217.

[101] Bach, A., Chi, C. N., Olsen, T. B., Pedersen, S. W., Røder, M. U., Pang, G. F., Clausen, R. P., Jemth, P., Strømgaard, K. (2008) Modified Peptides as Potent 
Inhibitors of the Postsynaptic Density-95/N-Methyl-d-Aspartate Receptor Interaction. J. Med. Chem. 51, 6450-6459.

[102] Bach, A., Chi, C. N., Pang, G. F., Olsen, L., Kristensen, A. S., Jemth, P., Stromgaard, K. (2009) Design and Synthesis of Highly Potent and PlasmaStable Dimeric Inhibitors of the PSD-95/NMDA Receptor Interaction. Angew. Chem. Int. Ed. 48, 9685-9689.

[103] Sainlos, M., Tigaret, C., Poujol, C., Olivier, N. B., Bard, L., Breillat, C., Thiolon, K., Choquet, D., Imperiali, B. (2011) Biomimetic divalent ligands for the acute disruption of synaptic AMPAR stabilization. Nat Chem Biol 7, 8191.

[104] LeBlanc, B. W., Iwata, M., Mallon, A. P., Rupasinghe, C. N., Goebel, D. J., Marshall, J., Spaller, M. R., Saab, C. Y. (2010) A cyclic peptide targeted against PSD-95 blocks central sensitization and attenuates thermal hyperalgesia. Neuroscience 167, 490-500.

[105] Piserchio, A., Salinas, G. D., Li, T., Marshall, J., Spaller, M. R., Mierke, D. F. (2004) Targeting specific PDZ domains of PSD-95; structural basis for enhanced affinity and enzymatic stability of a cyclic peptide. Chem. Biol. 11, 469-473.

[106] Udugamasooriya, D. G., Sharma, S. C., Spaller, M. R. (2008) A chemical library approach to organic-modified peptide ligands for PDZ domain proteins: a synthetic, thermodynamic and structural investigation. Chembiochem 9, 1587-1589.

[107] Hammond, M. C., Harris, B. Z., Lim, W. A., Bartlett, P. A. (2006) Beta strand peptidomimetics as potent PDZ domain ligands. Chem. Biol. 13, 1247-1251.

[108] Bach, A., Eildal, J. N., Stuhr-Hansen, N., Deeskamp, R., Gottschalk, M., Pedersen, S. W., Kristensen, A. S., Stromgaard, K. (2011) Cell-Permeable and Plasma-Stable Peptidomimetic Inhibitors of the Postsynaptic Density-95/NMethyl-d-Aspartate Receptor Interaction. J. Med. Chem. 54, 1333-1346.

[109] DeLano, W. L. (2002) The PyMOL Molecular Graphics

System. DeLano Scientific, San Carlos, CA, USA 


\section{FIGURE LEGENDS}

Fig. 1. Structural models of PDZ domains. (A) The NMR structure of SAP97 PDZ2 (pdb file: 2IOL) (37) shows the typical $\beta \beta \beta \alpha \beta \beta \alpha \beta$ fold of the PDZ domain, with the peptide ligand binding as an antiparallel strand to $\beta 2$. The numbering of peptide ligand residues starts at the C-terminus (position 0) and then $-1,-2$ etc. The evolutionarily conserved His384 hydrogen bonds to the side-chain of Thr-2 in the peptide ligand. The dashed lines indicate hydrogen bonds between the carboxylate of the C-terminus and the carboxylate-binding loop in the PDZ domain. (B) Example of a functional supramodule, that of ZO-1 PDZ3-SH3-GuK (pdb: 3SHW) (67). The figures were drawn in PyMol (109).

Fig. 2. Energy diagram for PDZ-ligand interactions. An induced fit mechanism was suggested for the binding of PTP-BL PDZ2 (33) and SAP97 PDZ2 (32) to a peptide ligand. The two barriers will appear as one for the binding reaction (left panel) except at very high ligand concentration (right panel) where the first-order transition, the conformational change, becomes rate limiting for the overall reaction.

Fig. 3. Comparison of selected predicted and experimental sparse networks in PDZ domains. The different colours depict a selection of experimental and computationally predicted amino acid networks in two PDZ domains, PTP-BL PDZ2 and PSD-95 PDZ3. Residue numbering starts from 1 for each PDZ and the secondary structure elements show the location of the network residues. The references are: Lockless and Ranganathan (50), Liu et al. (56), Gianni et al. (48), Gerek \& Ozkan (55), Fuentes et al. (47), Kong and Karplus (49) and Dhulesia et al. (57). 
Fig. 4. Structures and affinities of selected inhibitors of therapeutically relevant PDZ domains. $K_{\mathrm{d}}$ or $K_{\mathrm{i}}$ values are given below the structures unless otherwise stated. References: Joshi et al. (83), Fujii et al. (94), Lee et al. (98), Mayasundari et al. (85), Shan et al. (97), Thorsen et al. (81), Grandy et al. (95), Saupe et al. (82), Bach et al., 2009 (102), Bach et al., 2011 (108), Bach et al., 2012 (73), Long et al. (71), Sainlos et al. (103), Hammond et al. (107), Piserchio et al. (105), and Udugamasooriya et al. (106). 

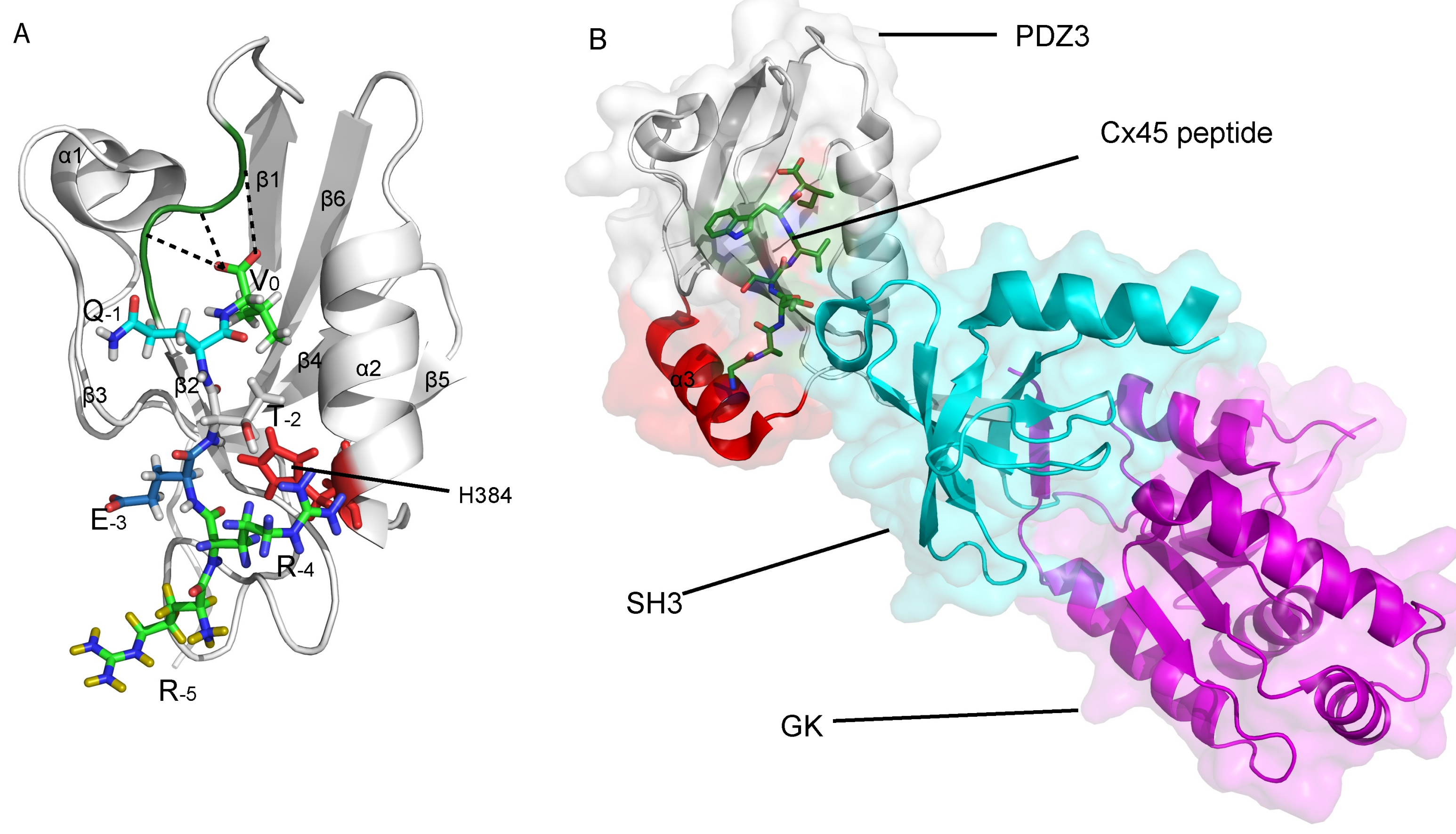

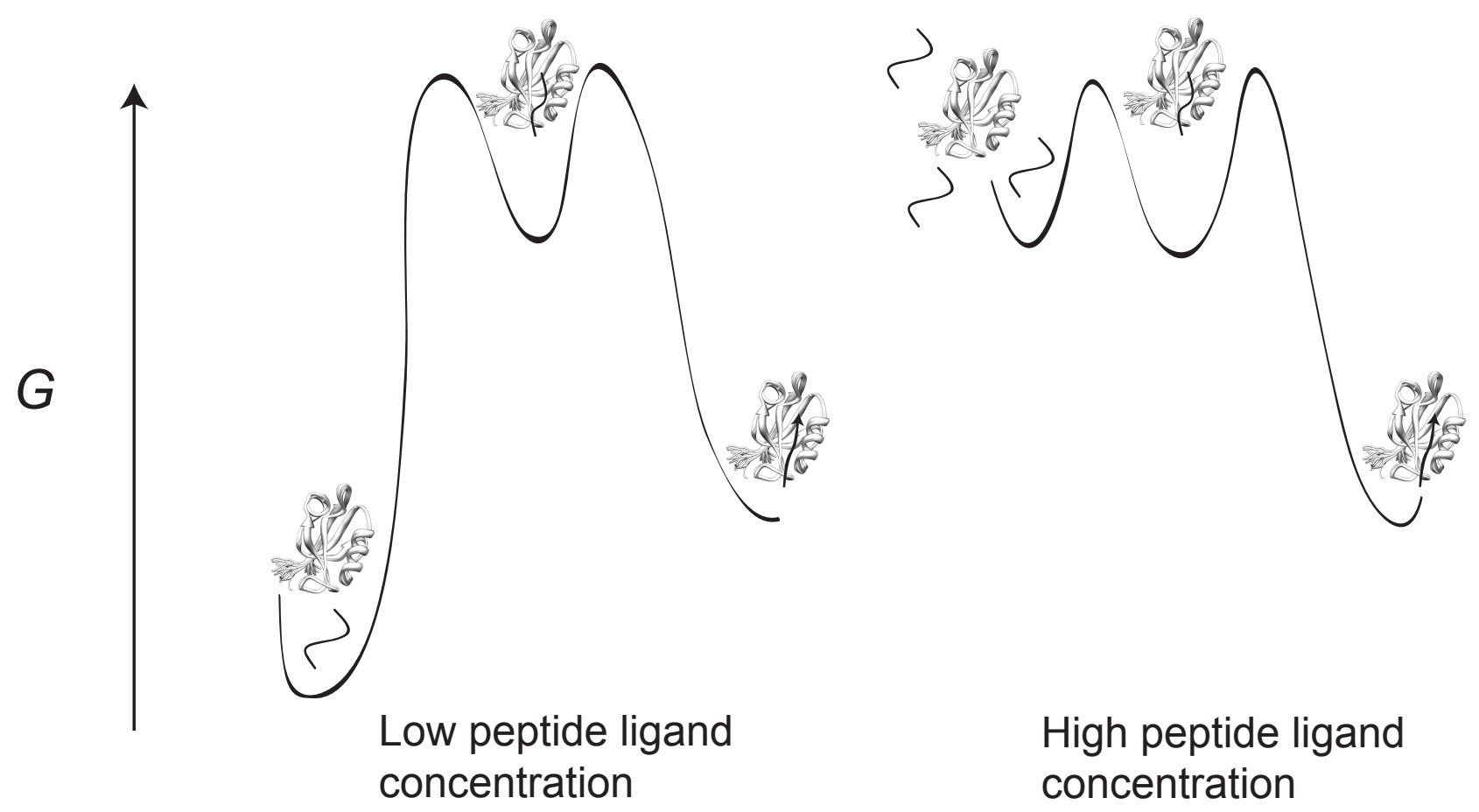

High peptide ligand concentration 
PSD-95 PDZ3

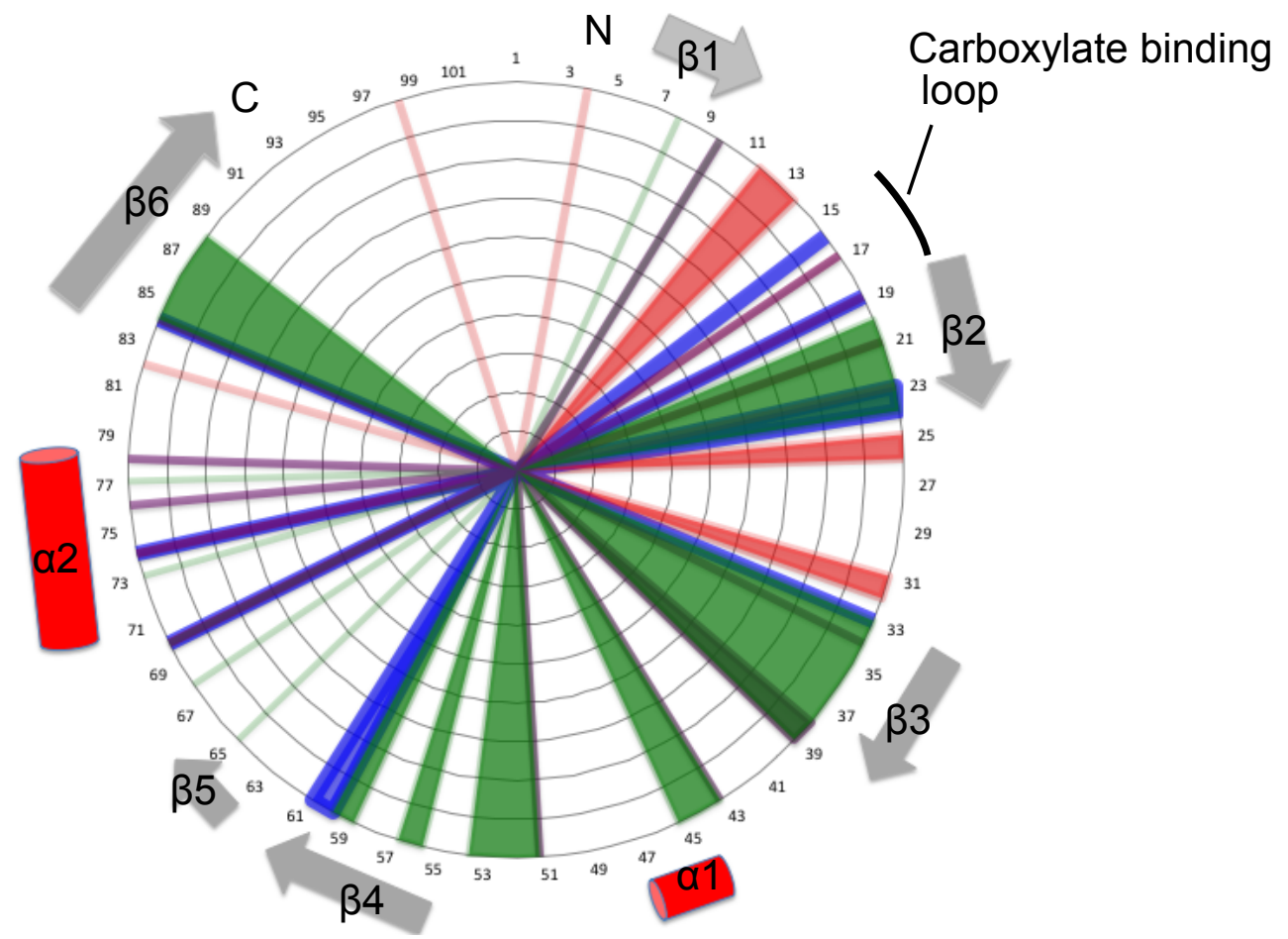

D Lockless \& Ranganathan

ㅁ. Liu et al.

- Gianni et al.

- Gerek \& Ozkan
PTP-BL PDZ2

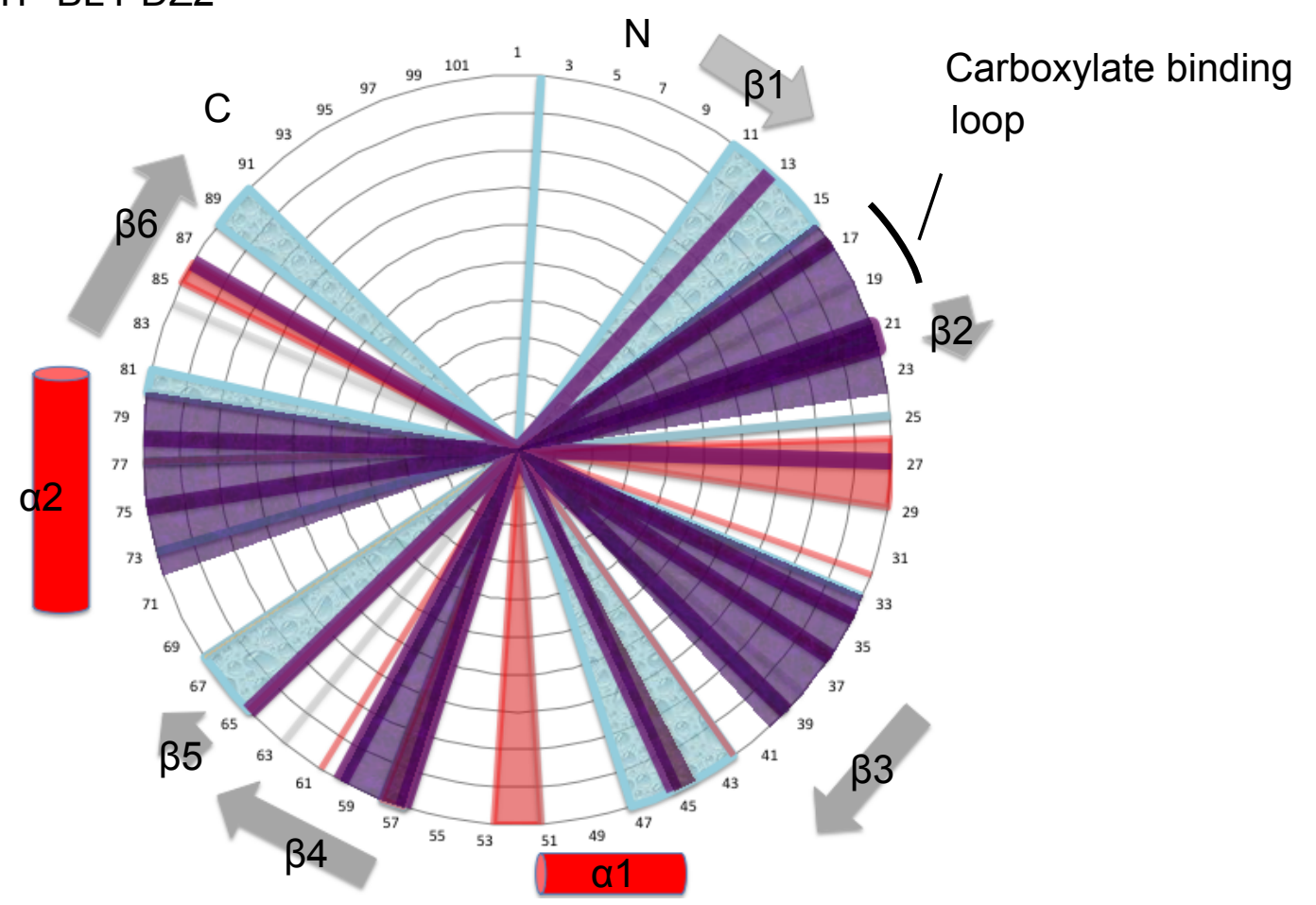

Kong \& Karplus

- Dhulesia et al.

(11) Fuentes et al.

- Gianni et al.

- Gerek \& Ozkan 
<smiles>O=C1NC(=S)SC1Cc1ccc(C(F)(F)F)cc1</smiles>

AF6 $(100 \mu \mathrm{M})$

(Joghi $\theta$ \& al., 2006)<smiles>CC1=CC(C(=O)N[C@@H](Cc2ccc(C)cc2)C(=O)N[C@@H](CC(C)C)C(=O)O)=CC(F)C1F</smiles>

(Shan et el., 2012)

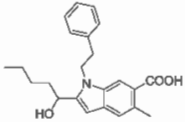

DM3 $(29 \mu \mathrm{M})$

(Fuji of el., 2007)<smiles>CCOC(=O)NC(=O)/C(C#N)=C/c1ccc(Cl)c(Cl)c1</smiles>

PICK1 $(10 \mu \mathrm{M})$

(Thorsen at al., 2010)

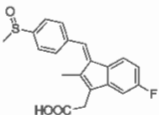

Dul1 (11 $\mu \mathrm{M})$ (Lee el el. 2009)<smiles>Cc1cc2c(CO)c(CCCCC(=O)O)n(CCc3ccccc3)c2cc1C(=O)O</smiles>

NHERF1 PDZ1 (IC:O $15 \mu \mathrm{M})$

(Mayasundari of A., 2003)

\section{Dimeric Inhibitors}

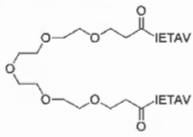

PSD-95 PDZ1-2 (0.010 بM)

(Bach et al., 2009)<smiles>CCN(CC)CCOCCOCCC(=O)C(F)F</smiles>

PSD-95 PDZ1-2 (0.0046 $\mu \mathrm{M})$ (Bach ot of +12012 )<smiles>O=C(Cc1ccccc1)Nc1cccc(C(=O)Nc2ccccc2C(=O)O)c1</smiles>

DN1 (11 $\mu \mathrm{M})$ (Grandy et at, 200日)<smiles>O=C(O)[C@@H]1Nc2c(O)cc(Cl)c([N+](=O)[O-])c2[C@]2(O)CC=C[C@H]12</smiles>

Shanks (10 $\mu \mathrm{M})$

(Saupe of al., 2011)

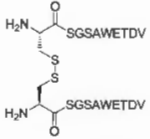

P5D-95 PDZ1-2 (ED $50.5 \mu \mathrm{M})$ (Long et 바., 2003)

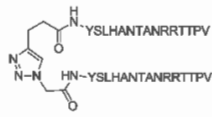

PSD-95 PDZ1-2 (0.81 $\mu \mathrm{M})$ (Sainlos at at., 2011)

\section{Peptidomimetics}<smiles>CC(C)C[C@H](NC(=O)C(CO)NC1=NC(=O)CN(C(=O)[C@H](CCCCN)NC(C)C)[C@H]1CCC(=O)O)C(=O)N[C@@H](C(=O)O)C(C)C</smiles>

a1-Syntophin $(0.32 \mu \mathrm{M})$

(Hammond et at., 2006)

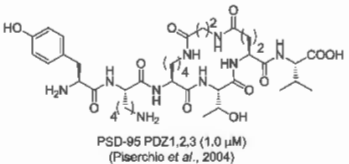

(Piserchio et al, 2004)

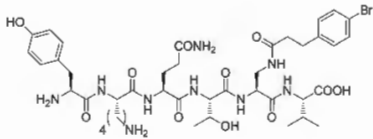<smiles>CC(C)[C@H](NC(=S)[C@H](C)NC(=O)[C@@H](NC(=O)[C@H](CCC(=O)O)NCCC1CCCCC1)C(C)O)C(=O)O</smiles>

PSD-95 PD72 \{0.63 $\mu \mathrm{M})$

(Bach of al, 2011) 